J. Egypt. Soc. Parasitol. (JESP), 51(1), 2021: 169 - 174

(Online: 2090-2549)

\title{
NEUROGENIC BLADDER DYSFUNCTION IN CHILDREN PROGRESS TO KIDNEY FAILURE IN ADOLESCENCE AND YOUNG AGE: PERSONALISED MENAGEMENT, REVIEW AND CASE SERIES
}

\author{
By
}

MOHAMED WISHAHI

Department of Urology, Theodor Bilharz Research Institute, Embaba P. O. Box 30, Giza, Egypt (Correspondence: moh.weshahy@gmail.com)

Abstract

Newborn infants who had neurogenic bladder dysfunction (NBD) have a normal upper urinary tract. Most of them will develop deterioration of renal function, and chronic kidney disease in case they do not received proper management. Renal damage is due to high detrusor pressures resulted from poor compliance of the bladder, beside detrusor over-activity against a closed sphincter or detrusor sphincter dyssynergia.

To preserve renal function and prevent deterioration of the kidneys, NBD must be treated immediately after being diagnosed. Over the last few years there was great progress in the treatment of children with the NBD. Neurogenic bladder dysfunction in children must be diagnosed early in life and the child should receive the proper management, neglecting the case or improper management would end with deleterious effect on the upper tract end with renal dysfunction and chronic kidney failure. There are different options for management. The type of management would be personalized for each case and could be modified. Case series were presented to illuminate the early management value of children with NBD in situation of unavailable of advanced methods of treatment.

The different approaches for management including the recent approaches were reviewed. This case series elaborate the management of 24 Egyptian children with NBD and impairment of renal function. The children underwent cutaneous vesicostomy at early stages of the disease. The procedure was feasible and protected the kidney from deterioration tell adolescence. This procedure is feasible in limited hospital resources and/or low-middle income countries.

Key words: Egyptian children, Neurogenic-bladder dysfunction, Kidney failure, Vesicostomy

\section{Introduction}

Newborn infants who had neurogenic bladder dysfunction (NBD) have a normal upper urinary tract (Kari et al, 2006). Most of them developed deterioration of renal function in case they were not properly treated (Filler et al, 2012). Renal damage was due to high detrusor pressures resulted from poor compliance of the bladder (Bauer, 2008), beside detrusor over-activity against a closed sphincter or detrusor sphincter dyssynergia (Amarante et al, 2012). To preserve renal function and prevent deterioration of kidneys, NBD must be treated immediately after being diagnosed. Over the last few years, there was great progress in children treatment with NBD (Drewiecki et al, 2011)

Neurogenic bladder dysfunction was classified to subcategories according to the urodynamic findings: 1- Sphincter over-activity combined with a detrusor inactivity causing incomplete bladder emptying. 2- Sphincter over-activity during detrusor contraction that led to affection and deterioration of upper tract. 3- Incompetent sphincter associated with detrusor inactivity leading to large bladder capacity, urine leakage, and incomplete emptying. 4- Detrusor hyperreflexia and loss of bladder compliance (Bauer et al, 1984; Lavallee et al, 2013).

Management of neurogenic bladder dysfunction in children:

Clean intermittent catheterization (CIC) in combination with anticholinergics (oxybutynin): It was considered the standard therapy for children with neurogenic bladder dysfunction (NBD) with detrusor hyperactivity This treatment was feasible and effective in developing countries (Jeruto et al, 2004), where untreated neuropathic bladder is an important cause of preventable chronic renal failure (Kari et al, 2006).

Complete bladder emptying with CIC prevent the occurrence of high-pressure voiding 
that affect kidney function. CIC requires proper education and training, good patient compliance on a long-term basis.

Oxybutynin suppresses detrusor hyperreflexia and eliminates uninhibited detrusor contractions leading to urinary leakage; prevented high-pressure bladder storage and high-pressure emptying. The frequent side effects of oxybutyrin as dry mouth lead most patients and particularly children to discontinue the treatment.

There is increasing evidence for a possible causal association between the chronic use of anticholinergics and the risk of developing dementia.

Intravesical Oxybuterin: Treatment with oral anti-muscarinic was effective, but some patients did not respond to oral medications or experience unacceptable side events (SEs) (Schroder et al, 2016).

Patients experienced intolerable SEs, would benefit from intravesical oxybutynin chloride which is an effective therapy for neurogenic bladder dysfunction (Lazarus et al, 2009; Schroder et al, 2008; 2016).

The effect of intravesical oxybuterins was often transient. Intra-vesical oxybutynin chloride solution was supplemented with hydroxypropyl cellulose (HPC), a mucosal adhesive substance, reduced systemic SEs, it is termed modified intra-vesical oxybutynin therapy, which proved to be safe and showed excellent efficacy (Saito et al, 2004; Hayashi et al, 2007). It reduces the absorption of oxybutynin from bladder mucosa and has fewer systemic SEs than intra-vesical oxybutynin chloride without HPC.

Intra-vesical oxybutynin hydrochloride (2.5 mg oxybutynin-hydrochloride/day) \& HPC was an effective and relatively safe longterm therapeutic option, children with detrusor over-activity and high intravesical pressure in filling phase, it was good option to improve continence and bladder compliance (Honda et al, 2019).

New anti-muscarinic drugs: They act against the muscarinic receptors on the wall of the detrusor muscle, relax it, and thereby decrease intra-vesical pressures and overactive contractions and indirectly increase functional bladder capacity.

Solifenacin: Solifenacin succinate is a competitive muscarinic receptor antagonist approved worldwide at daily doses of $5 \mathrm{mg}$ tablet for treated of OAB in children (Kay et $a l$, 2006). Once-daily oral suspension of solifenacin allowed greater dosing flexibility (Bolduc et al, 2010; Nadeau et al, 2014).

Once daily solifenacin oral suspension was well tolerated in children with $\mathrm{OAB}$ aged $5-<12$ yr. Solifenacin was also well tolerated in adolescents aged 12-<18yr. (Park et al, 2014). It was well tolerated and effective on pediatric populations (Newgreen et al, 2006; Tannenbaum et al, 2020)

Trospium: is approved for OAB patients aged $12 \mathrm{yr}$. Trospium proved its efficacy and dosage of $10,15,20$, or $25 \mathrm{mg}$ for managing bladder over-activity in children, but $10 \%$ of patients showed adverse effects (Lopez Pereira et al, 2003). Urodynamic investigations showed a significant increase in bladder capacity (Bürst et al, 2011).

Tolterodine: is available for children as a solution, or tablets. in children with neurogenic bladder, drug formulation and dosing were based on age (4 months to 4years, Tolterodine oral solution $0.2-2 \mathrm{mg}$ twice daily, 5-10years, oral solution $0.5-4 \mathrm{mg}$ twice daily, 11-16years (Reddy et al, 2008)

Propiverine hydrochloride: with its antimuscarinic and calcium-channel modulating properties proved to be efficient in OAB patients, whether children and adults, with a low rate $(<1.5 \%)$ of adverse events (Grigoleit et al, 2006). It was also evaluated during children long-term treatment with NBD at a dose of $0.7-0.8 \mathrm{mg} / \mathrm{kg}$ body weight/day. Proved to be superior tolerability of propiverine over oxybutynin, with comparable efficacy

(Schulte-Baukloh et al, 2012),

Onabotulinum toxin A (Botox-BTX-A):

The goal of NDO treatment was to have a safe bladder storage pressures to avoid kidney damage, detrusor pressure of $40 \mathrm{~cm} \mathrm{H}_{2} \mathrm{O}$ was considered a critical value above which 
there was increased risk of upper urinary tract dysfunction ending in renal damage (Snodgrass et al, 2010).

European Society for Pediatric Urology and the Studies showed its positive efficacy and safety in children with a dose up to 360 $\mathrm{U}$, and $32 \%-100 \%$ of them were continent, with maximum detrusor pressure reduction of $32 \%$ to $54 \%$, and below $40 \mathrm{cmH} 2 \mathrm{O}$ threshold (Austin et al, 2021). The dose of 6 $\mathrm{U} / \mathrm{kg}$ was well-tolerated and effective for NDD in children aged 5-17years. The $200 \mathrm{U}$ dose showed clinically significant greater improvement and increased the functional bladder capacity.

Patients may be considered for reinjection when the clinical effect of previous injection diminished (commonly 6-12 months). Repeat injections of botulinum toxin A did not lead to increased fibrosis risk in the bladder wall of children.

Neural stimulation: Long term outcome in children treated with the percutaneous tibial nerve stimulation (PTNS) for dysfunctional voiding and $\mathrm{OAB}$ showed good results even after 2 years, and treatment maintenance was indicated in $29 \%$ of children (Capitanucci et al, 2009).

PTNS can modulate the voiding and storage function of the bladder leading to an overall patients improvement of symptoms in $60 \%$ and $47 \%-56 \%$ improvement of filling and voiding function parameters with sustainable outcome on the long run. PTNS was not cost effective as a primary treatment compared to anti-muscarinic but is a good option in refractory $\mathrm{OAB}$ or when anti-muscarinic not tolerated. PTNS was minimally invasive and not costly (De Wall et al, 2017).

Augmentation cystoplasty \& ileal conduit: Urinary diversion and augmentation cystoplasty would be resorted to select cases and an initial step for renal transplantation.

Cutaneous vesicostomy: Cutaneous vesicostomy was reported to be the best treated for hostile bladder in myelodysplasia (Morrisroe et al, 2005).Younger patients in whom conservative bladder management fails may undergo vesicostomy to maintain low-pressure drainage. It is often temporary and reversed later in life when the child was managed with anti-cholinergic, and CIC with or without bladder augmentation.

Vesicostomy gave overall resolution improvement, or stabilization of the preoperative parameters. Hydronephrosis achieved complete resolution or stabilization of renal function. Patients with impaired renal function before surgery will have an improvement of kidney function-on after vesicostomy, which would be closed later. At closure time, bladder capacity of $>300 \mathrm{ml}$ did not need augmentation cystoplasty. Long-term vesicostomy outcomes in NBD patients were effective in reversing deleterious consequences when the conservative treatments failed (Sonda et al, 1980). Procedure was simple, well tolerated, and easily reversible.

Renal transplantation: Children with renal insufficiency due to dysfunctional bladder received a renal allograft and achieve good long-term results. Correction of structural urogenital abnormalities and optimization of emptying and storage functions of bladder must be achieved before renal transplantation. There was no specific technique for the urinary drainage of the transplanted kidney considered as a standard approach as stable lower urinary tract pressure, using the intermittent catheterization, the medical therapy, timed voiding, augmentation cystoplasty, and supra-vesical diversion. This approach must be customized for each child and the parents. Bladder augmentation or urinary diversion usually did not adversely affect the function and survival of grafts after renal transplantation if excellent compliance by children and parents was guaranteed (Broyer et al, 2004). Tunneled ureteral re-implantation at the time of transplantation as well as antibiotic prophylaxis in patients with dysfunctional urinary tract minimize the risk for urinary tract infections which may trigger the development of acute rejection episodes and contribute to manifestation of chronic allograft nephropathy (Adams et al, 2005). 


\section{Patients and Methods}

Total of 28 children with NBD were evaluated from January 1995 to November 2005 with a follow-up for 5- 10 year. They were 23 boys \& 5 girls, aged 2-4years-old with a mean of (3.6 years). Children were from Kena, Sohag, Beni-Suief, Giza, and Cairo Governorates. The initial investigation showed high values of creatinine and blood urea that was adjusted to their age, the ultrasonography showed bilateral uretero-hydronephrosis. They were managed initially with indwelling urethral catheter for 2 weeks, the kidney function improved, and the children showed general improvement. Removal of the indwelling catheter showed rise in kidney values. Parents were asked to manage the child with frequent clean intermittent catheterization (CIC) and oral oxybutynin adjusted dose to the child age. The parents were not compliant, and the children reported side effect of oxybutynin that was mainly dry mouth. The case was explained to the parents and offered the option of cutaneous vesicostomy, they approved treatment and gave informed consent.

Operative procedure: Vesicostomy stoma site was selected near the umbilicus, a $3 \mathrm{~cm}$ long $x 2 \mathrm{~cm}$ width of U-shaped incision was made below the umbilicus to raise a cutaneous flap. A $3 \mathrm{~cm}$ vertical incision was made, urinary bladder identified after filling it with saline, an incision in made in the bladder dome, U-shaped skin flap was sutured to sided of bladder incision the other two sides of bladder wall were anastomosed to the skin edges. This procedure facilitates easy passage of suprapubic indwelling catheter when indicated. Being located at the dome of the bladder it prevents total incontinence, while the child can pass urine via the urethra. In high detrusor pressure, bladder was empty by vesicostomy stoma that allowed children to have diapers and to go back to school (Figs. 1, \& 2).

\section{Results}

Children and their mothers were successfully trained how to care for abdominal stoma.
Children were followed up every 6 months with valuation of kidney function, $\mathrm{CBC}$, and growth scale as a marker for good kidney function. Four out of the 28 patients were excluded from the study due to loss of followup. Six children developed chronic renal failure at ages of 10 years and were on regular hemodialysis. Eighteen reached puberty ages with compensated kidney function, undergone vesicostomy closure, and bladder capacity ranged from 350 to $400 \mathrm{ml}$.

\section{Discussion}

The recent development in pharmaceutical manipulation and treatment of NBD in children, and the newly therapeutic access for treatment with neural stimulation, these new facilities offer preservation of kidney function and good quality of life. These facilities are not routinely available in hospitals with limited resources and in low and / or lowmedium income countries, a different approach would be considered in management of children with NBD in developing countries (Kari, JA, 2006). There are different options for management of NBD in children that varied from Clean intermittent catheterization combined with oxybutynin, Intravesical oxybutynin, new anti-muscarinic drugs , onabotulinum toxin A, neural stimulation, augmentation cystoplasty or ileal conduit, vesicostomy, and lastly renal transplantation, choice of a treatment modality of this option is guarded with availability, costs, and experience of treatment team. Application of any of them. Clean intermittent catheterization (CIS) is feasible and effective in developing countries (Jeruto et al, 2004), but most children are not able to perform CIC, where this task is taken by the mother, which is not completely dedicated to do this job, particularly working women and women in rural areas.

Facing the problem of costs and noncompliance of parent or the child would raise the option of a simple, safe, procedure with minimal expenses, vesicostomy would be the best option in lack of facilities and in special situation. The result of treatment of 
28 children with NBD with cutaneous vesicostomy proved to be of good outcome. Limitation of this case series it its nature of retrospective nature, and it did not utilize the recent treatment modalities. The positive results of this series were the outcome of preserved the kidney function in long term follow-up and that it was applied successfully in low hospital resources.

\section{Conclusion}

Neurogenic bladder dysfunction in children must be diagnosed early in life and receive the proper management, as neglected case or improper management would lead to deleterious effect on upper tract with renal dysfunction and chronic kidney failure. There were different options for management. Management type would be personalized for every case and could be changed accordingly. Cutaneous vesicostomy is an alte-rnative to the recent advanced treatment facilities which can be applied in situation of limited hospital resources and in specific situations.

\section{References}

Adams, J, Mehls, O, Wiesel, A, 2005: Pediatric renal transplantation and the dysfunctional bladder. Transplant. Inter. https://doi.org/10.1111/j. 1432-2277.2004.tb00392.x.

Alloussi, S, Murtz, G, Braun, R, et al, 2010: Efficacy, tolerability, and safety of propiverine hydrochloride in comparison to oxybutynin in children with urge incontinence due to overactive bladder: results of a multicentre observational cohort study. BJU Int. 106:550-6.

Amarante, MA, Shrensel, JA, Tomei, KL, Carmel, PW, Gandhi, CD, 2012: Management of urological dysfunction in pediatric patients with spinal dysraphism: Review of the literature. Neurosurg. Focus 33:E4-8.

Austin, PF, Franco, I, Dobremez, E, et al, 2021: Onabotulinumtoxin A for the treatment of neurogenic detrusor over-activity in children. Neurourol. Urodyn. 40:493-501.

Bauer, SB, 2008: Neurogenic bladder: Etiology and assessment. Pediatr. Nephrol. 23:541-51.

Bauer, SB, Hallett, M, Khoshbin, S, Lebowitz, RL, Winston, KR, et al, 1984: Predictive value of urodynamic evaluation in newborns with myelodysplasia. JAMA 252:650-2.

Bolduc, S, Moore, K, Nadeau, G, et al, 2010:
Prospective open label study of solifenacin for overactive bladder in children. J. Urol. 184: 1668-73.

Broyer, M, LeBihan, C, Charbit M, Guest, G, Tete, MJ, et al, 2004: Long-term social outcome of children after kidney transplantation. Transplantation 77:1033-7.

Bürst, M, Wolf, A, 2011: Efficacy and safety of trospium chloride use in children with idiopathic and neurogenic detrusor over-activity: An overview of available data. Urotoday Int. J. 4, 1:17. doi:10.3834/ uij.1944-5784.2011.02.17.

Capitanucci, ML, Camanni, D, Demelas, F, Mosiello, G, Zaccara A, et al, 2009: Long-term efficacy of percutaneous tibia nerve stimulation for different types of lower urinary tract dysfunction in children. J. Urol. 182:2056-61.

Cohen, J, Hardback, L, Kaplan, G, 1978: $\mathrm{Cu}$ taneous vesicostomy for temporary urinary diversion in infants with neurogenic bladder dysfunction. J. Urol. 119:120-1.

De Wall, LL, Heesakkers, J PFA, 2017: Effectiveness of percutaneous tibial nerve stimulation in the treatment of overactive bladder syndrome. Res. Rep. Urol. 9:145-57.

Drzewiecki, BA, Bauer, SB, 2011: Urodynamic testing in children: Indications, technique, interpretation and significance. J. Urol. 186:1190-7.

Filler, G, Gharib, M, Casier, S, Lödige, P, Ehrich, JH, Dave, S, 2012: Prevention of chronic kidney disease in spina bifida. Int. Urol. Nephrol. 44:817-27.

Grigoleit, U, Murtz, G, Laschke, S, Scheldt, M, Goepel, M, et al, 2006: Efficacy, tolerability, and safety of propiverine hydrochloride in children and adolescents with congenital or traumatic neurogenic detrusor over-activity: A retrospective study. Eur. Urol. 49:1114-20.

Guerra, LA, Moher, D, Sampson, M, Barrowman, N, Pike, J, Leonard, M, 2008: Intravesical oxybutynin for children with poorly compliant neurogenic bladder: A systematic review. J. Urol. 180:1091-7.

Hayashi, A, Saito, M, Okada, S, Hanada, T, Watanabe, T, et al, 2007: Treatment with modified intra-vesical oxybutynin chloride for neurogenic bladder in children. J. Pediatr. Urol. 3: 438-42.

Honda, M, Kimura, Y, Tsounapi, P, Hikita, K, Saito, M, et al, 2019: Long-term efficacy, safety, and tolerability of modified intra-vesical oxybutynin chloride for neurogenic bladder in children. J. Clin. Med. Res. 11:25660-4. 
Jeruto, A, Poenaru, D, Bransford, R, 2004: Clean intermittent catheterization: Overview of results in 194 patients with spina bifida. Afr. J. Pediatr. Surg. 1:20-3.

Kari, JA, 2006: Neuropathic bladder as a cause of chronic renal failure in children in developing countries. Pediatr. Nephrol. 21:517-20.

Katz, IR, Sands, LP, Bilker, W, et al, 1998: Identification of medications that cause cognitive impairment in older people: The case of oxybutynin chloride. J. Am. Geriatr. Soc. 46:8-13.

Kay, G, Crook, T, Rekeda, L, et al, 2006: Differential effects of the anti-muscarinic agents darifenacin and oxybutynin ER on memory in older subjects. Eur. Urol. 50:317-26.

Lavallée, LT, Leonard, MP, Dubois, C, Guerra, LA, 2013: Urodynamic testing: Is it a useful tool in the management of children with cutaneous stigmata of occult spinal dysraphism? J. Urol. 189:678-83.

Lazarus, J, 2009: Intravesical oxybutynin in the pediatric neurogenic bladder. Nat. Rev. Urol. 6: 671-4.

Morrisroe, SN, O'Connor, RC, Nanigian, DK, Kurzrock, EA, Stone, AR, 2005: Vesicostomy revisited: The best treatment for the hostile bladder in myelodysplastic children? BJU Int. 96:397-400.

Nadeau, G, Schroder, A, Moore, K, et al, 2014: Long-term use of solifenacin in pediatric patients with overactive bladder: Extension of a prospective open-label study. Can. Urol. Assoc. J. 8:118-23.

Newgreen, D, Bosman, B, Hollestein-Havelaar, A, et al, 2017: Solifenacin in children and adolescents with overactive bladder: Results of a phase 3 randomized clinical trial. Eur. Urol. 71: 483-90.
Park, SJ, Pai, KS, Kim, JM, et al, 2014: Efficacy and tolerability of anticholinergics in Korean Children with overactive bladder: a multicenter retrospective study. J. Korean Med. Sci. 29: 1550-4.

Reddy, PP, Borgstein, NG, Nijman, RJ, Ellsworth, PI, 2008: Long-term efficacy and safety of tolterodine in children with neurogenic detrusor over-activity. J. Pediatr. Urol. 4:428-33.

Saito, M, Watanabe, T, Tabuchi, F, Otsubo, K, et al, 2004: Urodynamic effects and safety of modified intravesical oxybutynin chloride in patients with neurogenic detrusor over-activity: 3 years' experience. Int. J. Urol. 11:592-6.

Schroder, A, Albrecht, U, Schnitker, J, Reitz, A, Stein, R, 2016: Efficacy, safety, and tolerability of intravesically administered $0.1 \%$ oxybutynin hydrochloride solution in adult patients with neurogenic bladder: A randomized, prospective, controlled multicenter trial. Neurourol. Urodyn. 35:582-8.

Schulte-Baukloh, H, Mürtz, G, Heine, G, et al, 2012: Urodynamic effects of propiverine in children and adolescents with neurogenic bladder: Results of a prospective long-term study. J. Pediatr. Urol. 8:386-92.

Snodgrass, WT, Gargollo, PC, 2010: Urologic care of the neurogenic bladder in children. Urol. Clin. North Am. 37:207-14.

Sonda, LP, Solomon, MH, 1980: Twenty-year outcome of cutaneous vesicostomy. J. Urol. 124: 326-8

Tannenbaum, S, Adel, M, Krauwinkel, W, et al, 2020: Pharmacokinetics of solifenacin in pediatric populations with overactive bladder or neurogenic detrusor overactivity. Pharmacol. Res. Perspect. e00684. https://doi.org/10.1002/pr p2.684.

\section{Explanation of Figures}

Fig. 1: Operative photograph showed last step in procedure of cutaneous vesicostomy where site of stoma near umbilicus and a U shaped skin inserted in tract to facilitate passage of a catheter.

Fig. 2: Follow-up of cutaneous vesicostomy in a child with neurogenic bladder dysfunction showed site of vesicostomy opening in abdominal wall close to umbilicus, with advantage that child voluntarily void via vesicostomy opening, and not become totally incontinent.

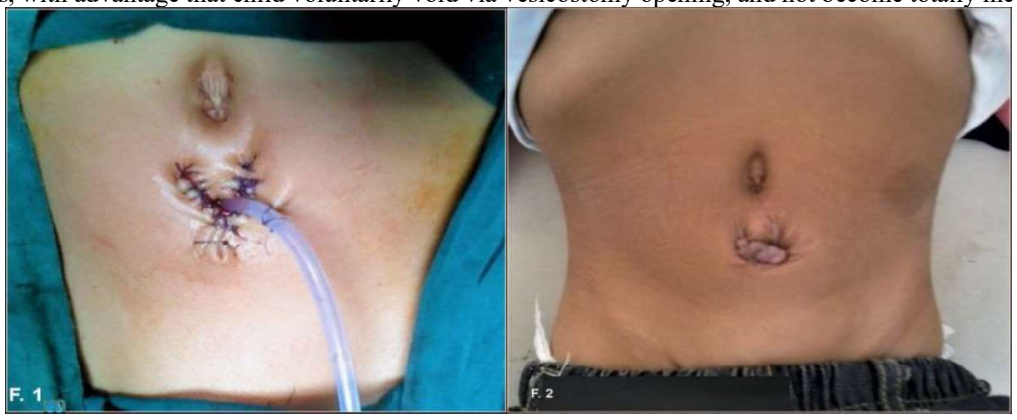

